\title{
Two Forms of Experimental Simulation Analysis for Multiaxial Drilling Efforts in the Time Domain Model
}

\author{
Dionísio José Rodrigues da Costa ${ }^{1 *}$, Jose Flávio Feiteira ${ }^{2}$, Jorge A. R. Duran ${ }^{1,2}$ and Ladário da Silva ${ }^{1,3}$ \\ 1. Department of Metallurgical and Mechanical Engineering, Fluminense Federal University, Volta Redonda, 27255-125, Brazil \\ 2. Department of Mechanical Engineering, Fluminense Federal University, Volta Redonda, 27255-125, Brazil \\ 3. Department of Physics, Exact Sciences Institute, Fluminense Federal University, Volta Redonda, 27213-145, Brazil
}

\begin{abstract}
This study proposes an analysis of the machining efforts based on experimental strains results, in the time domain. We have developed the design and construction of two prototypes: a DP (Dynamic prototype) and a SP (Static prototype), which were submitted simultaneously to the same conditions of efforts produced during a full drilling operation with twist drill. Machining tools and electric resistive SGs (Strain gauges) were adapted in the tepped rotary shaft DP. In order to form electrical contacts in a dynamic way, a set of SR (Slip rings) was designed. A SP (Second prototype), developed for fixing the specimen, had a static shaft, without geometric variation, allowing a straightforward electrical connection with the SGs. The prototypes were adjusted to the center line of a radial drilling machine. The differentiated ways that SGs were arranged and interconnected to the WB (Wheatstone bridge) have established the condition, so that the DP only strains produced by twisting. In SP, on the other way, the SGs were adjusted in order to assimilate all the influence efforts influences produced during a machining process. The acquired analogic signal reproduced strains in both shafts, in a consistent way, with multi-axial loading patterns, which are satisfactorily related to the analytical results.
\end{abstract}

Key words: Vibration, strain gauges, drilling efforts, slip ring, dry machining.

\section{Introduction}

Several studies regarding the drilling operation have been developed in order to predict more accurately on these fundamental efforts, tooling behavior and its vibration influence on the process and quality of the finishing operation. The work presented by CASTRO et al. [1] proposed an original method to measure dynamic forces using a commercial piezoelectric dynamometer. This approach is based on the construction of a correction function, taking into account the dynamic behavior of the mechanical environment. It allows the measurement of shear forces to a large frequency domain, which has application in high-speed machining and cutting processes instabilities. KARABY [2] has studied the criteria and results in strain gages position. These strain

\footnotetext{
"Corresponding author: Dionísio Jose Rodrigues da costa, master and academic Ph.D., materials engineering, research fields: stress and dynamic strains based on not destructive experimental analysis.
}

gates were connected by static contacts in specially designed dynamometers, appropriated for analysis of basic forces in various machining processes. DU et al. [3], in his paper, presented a computer simulation model for drilling and reaming processes. The model is made of four parts: 1) The force model for the cutting lips; 2) The force model for the chisel edge; 3) The dynamic model for the machine tool (including the cutter) and 4) The regenerative correlation between the force and machine tool vibration. The models for the forces and the machine tool are similar to the existing models. The key to the model is the regeneration correlation between cutting forces and machine tool vibration. The model can predict the dynamic forces and chatter limit. It also reveals several interesting phenomena, such as how the feed and the point angle of the drill affect the chatter limit. The simulation results are validated experimentally by both drilling and reaming under various cutting conditions. MOUSAVI [4] analyzed the drilling deep holes with 
small diameters, to adopt an alternative answer to the chip evacuation problem. In order to use a vibratory drill head, self-vibratory cutting conditions are set focusing drill geometry parameters and the cutting twist effect on impulse power. ROUKEMA, et al. [5, $6]$, in their articles, produced a model in the time domain of torsional and axial vibrations in the drilling. A cutting force model is used to predict torque as function of the feed rate, the radial depth of cut and the drill geometry. The distribution of the chip thickness is affected by the rigidity and by the drill body motion and structural vibrations. Force, torque, power and error dimensional shape left on the surface are taken into account in the dynamic kinematic model for foreseeing the chip thickness. The stability of the drilling process is also evaluated using the simulation model in the time domain. A irregular surface finishing can be simulated for actual drilling considering the damping process. SANTOS et al. [7] applied to electrical contacts, statically in the twisting machine design, with low manufacturing cost, in order to evaluate Young's modulus by torsion tests for materials. STRENKOWSKI, J. S. et al. [8] have made a comprehensive study of the dynamic kinematic modelling and stability in the drilling operations. Their study has focused on the stability of the drilling in the frequency domain. Considering the motion of the rigid body, torsional-axial and lateral vibrations in the drilling and formation of the resulting hole drilling operation, an analytical finite element technique was developed to predict the feed force and torque in drilling. HUANG et al. [9] analyzed the quality of drilling by varying the vibration in the drill tip for a drilling process in machining at high speed. Thus, they used a pre-twisted bar to simulate a drill bit. They proposed a drilling process analysis that is grounded by an elastic movement Winkler type - Type which elastic movement. This movement is characterized by one boundary condition at the drill tip in the bore. Due to the variation of the depth of drilling, a dynamic model dependent on the time was proposed. Simulated results from this proposed model indicated that sudden natural frequencies identified as problematic will take place resulting in a severe induced vibration. ZEILMANN et al. [10] reported a study of the effects of the absence of using of cutting fluids in steel-fast-M2 HSS tools, in machining steel AISI P20. The main objective of this paper is to produce analysis based on strains generated by drilling efforts. The shaft that transmits torque behaves like a torsional spring, which depending on the applied dynamic loading and natural system frequencies may cause cyclic vibration. In this context, based on the studies referenced above, this study established two different experimental dynamic analysis. One analysis uses SGs and SRs system while the other one used only SGs. Both analysis measure, strains in transmission power shaft surface under multiaxial loading produced by machining process. Initially, two prototypes were designed with a main SP and a DP shaft, considering theoretical drilling efforts, specified in Eqs. (1-3), resulting in two distinct forms of analysis and assembly. One produced by static electrical contact applied to SP and another one that requires a dynamic electrical contact applied to the DP. This form of dynamic contact that based on SRs system was designed and manufactured exclusively for this purpose, as exhibited in Fig. 1.

In the process of experimental analysis, strain graphics proportional to machining efforts were produced, variable in time, which determined an actual combined loading cyclic compression and torsional moment. These strains were acquired in a single point of SP and DP shaft surface.

For the analysis phase of each experimental procedure, it was considered the following parameters referenced in Table 1. Setting a limit of machining forces, minimum and maximum, in the drilling process, where, $F_{c}$ represents the cutting force and it was related to the torsional moment Eqs. (1-5). Thus, these equations establish the form request multiaxial composed 


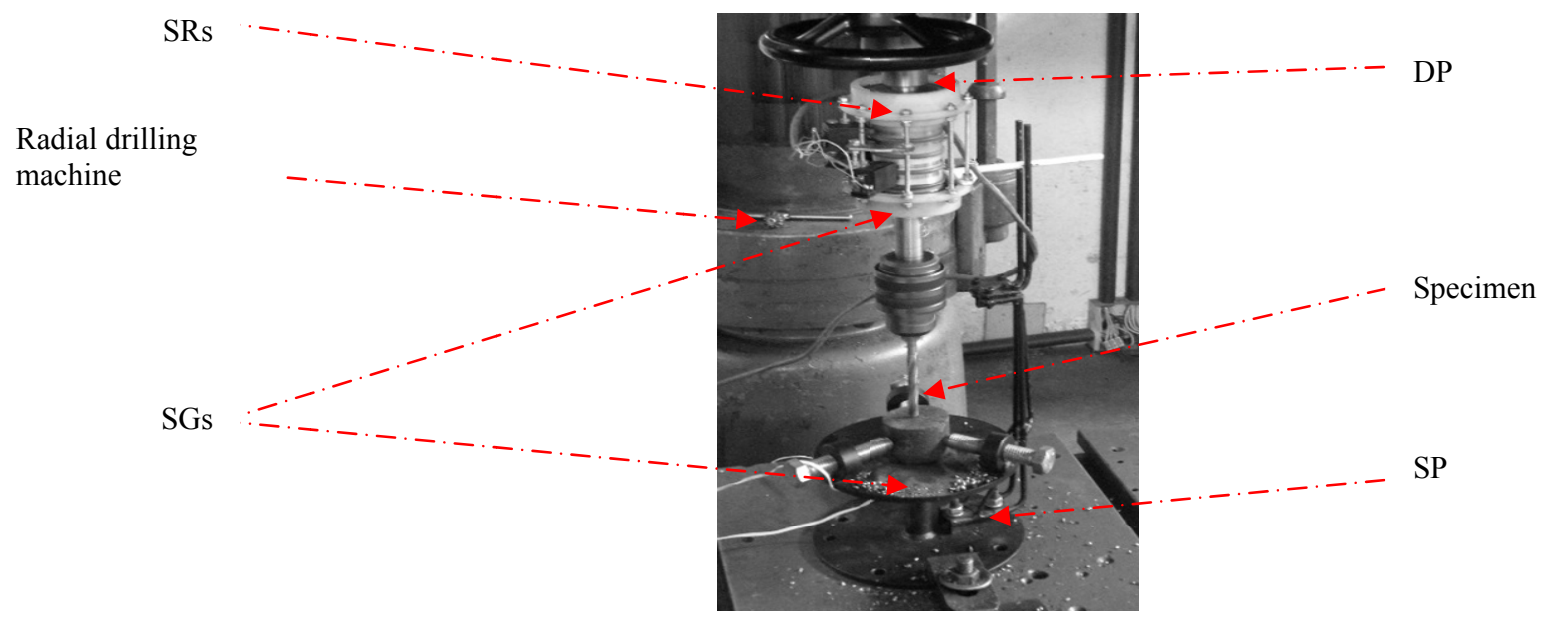

Fig. 1 General arrangement (PD and PE).

Table 1 Parameters of the drilling process in full.

\begin{tabular}{lllllll}
\hline $\mathbf{N}$ & $\mathbf{F}$ & $\mathbf{V}_{\mathbf{C}}$ & $\mathbf{V}_{\mathbf{F}}$ & $\mathbf{L}$ & $\mathbf{t}_{\mathbf{C}}$ & $\mathbf{F}_{\mathbf{F}}$ \\
\hline $\mathrm{rpm}$ & $\mathrm{mm} / \mathrm{rot}$ & $\mathrm{m} / \mathrm{min}$ & $\mathrm{mm} / \mathrm{min}$ & $\mathrm{mm}$ & $\min$ & $\mathrm{KN}$ \\
260 & 0.05 & 10.4 & 13.0 & 23 & 1.8 & $1.260 / 1300$ \\
\hline
\end{tabular}

Where, $\mathrm{N}=$ Spindle speed; $\mathrm{f}=$ Feed rate; $\mathrm{E}=$ Young's modulus; $\mathrm{V}_{\mathrm{f}}=$ Thrust speed; $\mathrm{L}=$ Hole depth; $\mathrm{t}_{\mathrm{c}}=$ Time cutting; $\mathrm{V}_{\mathrm{c}}=$ Cutting speed.

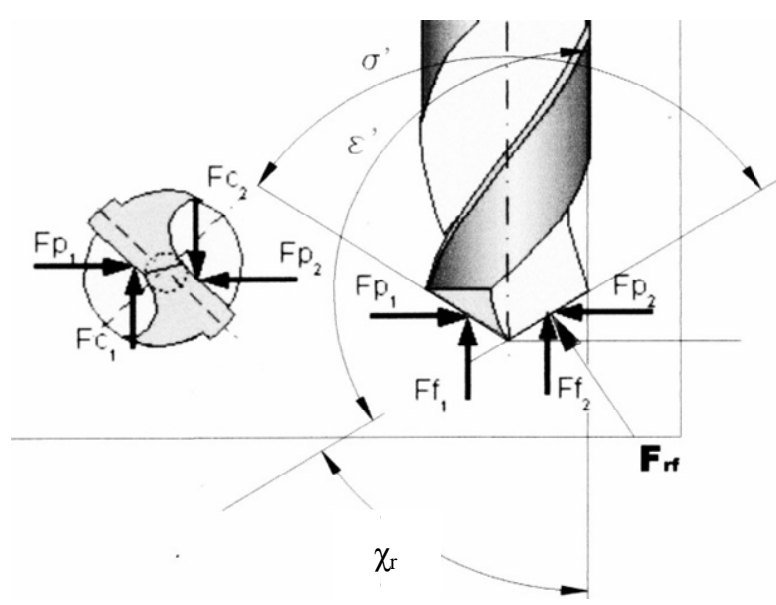

(a)

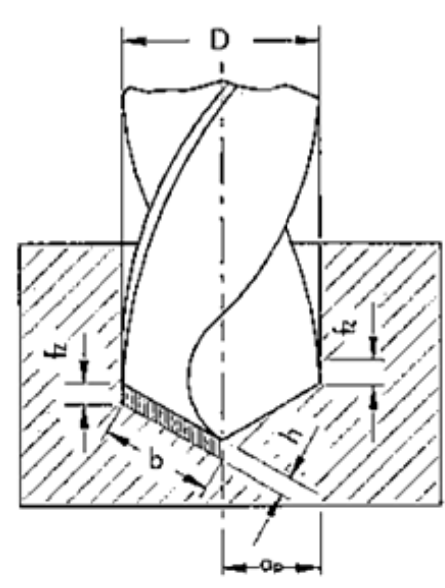

(b)

Fig. 2 Force's representation produced by the tooling in a drilling process: (a) cutting drill tip details and (b) DINZ [11].

of basic tooling forces to the machining process, Fig. $1 \mathrm{~b}$.

In the used analytical process in order to establish maximum and minimum limits for the peak amplitude, variations effort parameters invariable over time were adopted.

The forces checked the drill machining process are basically: $\mathbf{F}_{\mathbf{f}}$ thrust force produced in the axial direction of the tool (for the forward movement), $\mathbf{F}_{\mathbf{p}}$ passive force produced in the radial tool direction. Due to the symmetry of the components of the final total force tool $\left(\mathrm{F}_{\mathrm{P} 1}\right.$ and $\left.\mathrm{F}_{\mathrm{P} 2}\right)$, observed in the second cutting edges are canceled. Resulting in the $\mathrm{F}_{\mathrm{c} 1}$ and $\mathrm{F}_{\mathrm{c} 2}$ components of cutting forces, which represented the moment torcional moment $\mathrm{M}_{\mathrm{t}}$. Thus, the efforts $\mathbf{F}_{\mathbf{c}}, \mathbf{F}_{\mathbf{f}}$ and $\mathbf{F}_{\mathbf{p}}$ were components of the total force end $\mathbf{F}_{\mathbf{t c}}$. Fig. 2a showed forces and its components, where: $F_{c i}$ resistance cutting force material in the main cutting edges; $F_{p i}$ - resistance cutting and compression force of the transverse cutting edge, $\mathrm{F}_{\mathrm{fi}}$ - resistance force due to friction of the guides drill with the surface hole 
and the chip with the drill exit surface, Fig. $2 b$.

$$
\mathrm{F}_{\mathrm{rfi}}=\mathrm{F}_{\mathrm{ci}}+\mathrm{F}_{\mathrm{pi}}+\mathrm{F}_{\mathrm{fi}}
$$

Because of the resistance forces, the total final moment was represented by the equation:

$$
\begin{aligned}
& \mathrm{M}_{\mathrm{ti}}=\mathrm{M}_{\mathrm{rfi}}+\mathrm{M}_{\mathrm{pi}}+\mathrm{M}_{\mathrm{ati}} \\
& \mathrm{M}_{\mathrm{ti}}\left(\mathrm{k}_{\mathrm{s}_{1}}, \mathrm{f}, \mathrm{a}_{\mathrm{p}}, \chi_{\mathrm{r}}, \mathrm{D}\right) \rightarrow \mathrm{M}_{\mathrm{t}}(\mathrm{t}) \\
&= \mathrm{k}_{\mathrm{s}_{1}}\left(\frac{(\mathrm{f}(\mathrm{t}))}{2} \cdot \operatorname{sen} \chi_{\mathrm{r}}\right)^{1-\mathrm{z}} \frac{\mathrm{a}_{\mathrm{p}}}{\operatorname{sen} \chi_{\mathrm{r}}} \cdot \frac{\mathrm{D}}{2} \\
& \rightarrow \mathrm{C}_{1}=\mathrm{k}_{\mathrm{s}_{1}} \frac{\left(\operatorname{sen} \chi_{\mathrm{r}}\right)^{1-\mathrm{z}}}{4 \cdot \operatorname{sen} \chi_{\mathrm{r}}} \\
& \mathrm{M}_{\mathrm{ti}}(\mathrm{t})=\mathrm{C}_{1} \times(\mathrm{f}(\mathrm{t}))^{1-\mathrm{z}} \times \mathrm{D}^{2} \\
& \mathrm{M}_{\mathrm{ti}}\left(\mathrm{f}, \mathrm{C}_{1}, \mathrm{y}_{1}, \mathrm{x}_{1}, \mathrm{D}\right) \rightarrow \mathrm{M}_{\mathrm{t}}(\mathrm{t})=\mathrm{C}_{1} \times \mathrm{f}^{\mathrm{y}_{1}}(\mathrm{t}) \times \mathrm{D}^{\mathrm{x}_{1}} \\
& \mathrm{~F}_{\mathrm{fD}}\left(\mathrm{f}, \mathrm{y}_{2}, \mathrm{x}_{2}, \mathrm{D}\right) \rightarrow \mathrm{F}_{\mathrm{fd}}(\mathrm{t})=\mathrm{C}_{2} \times \mathrm{f}^{\mathrm{y}_{2}}(\mathrm{t}) \times \mathrm{D}^{\mathrm{x}_{2}}
\end{aligned}
$$

where, $\mathrm{M}_{\mathrm{ti}}$ was the produced time due to cutting resistance strength of the material by the main cutting edges, $\mathrm{M}_{\mathrm{pi}}$ was produced time due to the shear strength of the material strength by transverse cutting edges, $\mathrm{M}_{\mathrm{ati}}$ was the moment produced due to the frictional force produced by surface hole and the chip with the drill exit surface.

In the above equations, the parameters $\mathrm{x}_{1}, \mathrm{x}_{2}, \mathrm{y}_{1}, \mathrm{y}_{2}$, $\mathrm{C}_{1}, \mathrm{C}_{2}$ and $0.7 \leq(1-\mathrm{z}) \leq 0.8$ were empirical constants based on the material shaft (SAE 1020), and referenced by DINIZ [11]; where, $\chi_{\mathrm{r}}$ was the tip angle of the drill tip in relation to its longitudinal axis, D was the drill diameter, $a_{p}$ was the tool radius and $K_{S 1}$ was the specific cutting pressure. Constants $\mathrm{C}_{1}=15.1$ \pm 0.4 and $C_{2}=32.5 \pm 0.4$ showed tolerance's variations in relation to their nominal values. For this reason, it was generated Table 2. In this table, torsional moment variation and cutting force based on Kronenberger Eq. (4) and Kienzle Eq. (3) were set as maximum and minimum values. This condition was allowed to consider in this study, the highest $\mathrm{M}_{\mathrm{t}}$ and the lower value of $\mathrm{M}_{\mathrm{t}}$ value as limit, invariable on time, to be applied to the graphs obtained from efforts experimentally way. The same proposition was applied to the thrust force $\mathrm{F}_{\mathrm{fD}}$ based on Daar Eq. (5).

\section{Methods and Materials}

The dynamic operation process was set by dry drilling which used a full radial drilling machine and tooling of the type twist drill $((\Phi)=12.5 \mathrm{~mm})$ type. The shafts strains produced in rotational and static way were identified and processed by analog signal into a digital signal device, using a signal conditioner manufactured by HBM model Spider 8-SR-30. The Catman Easy 3.0 software allowed acquisition and processing of the digital data. Programs made in Matlab, allowed independent graphics production for the behavior of forces in relation to the torcional moment and the thrust force. The strain gages arrangement in the DP shaft, Fig. 4a, examines only specific strains related to torcional moment in order to compare its results with the limits established by the timeless Kienzle-Kronenberg equation. SP's shaft, Fig. $4 \mathrm{~b}$, considered all biaxial effect request.

\subsection{SP Arrangement}

For attachment of the specimen to be machined by drilling $(50 \mathrm{~mm}$ diameter and $60 \mathrm{~mm}$ high, manufactured in SAE 1020 steel), a SP was designed and developed to be adapted on the basis of radial drilling machine, submitting it, simultaneously, to the same DP machining efforts. This prototype, in its

\begin{tabular}{|c|c|c|c|c|c|c|c|c|}
\hline \multicolumn{2}{|c|}{$\mathbf{M}_{\mathrm{ti}-(\text { Kienzle) }}$} & \multicolumn{2}{|c|}{$\mathbf{M}_{\mathrm{ti}-(\text { Kronenberg })}$} & \multicolumn{2}{|c|}{$\mathbf{F}_{\mathrm{C}}$ (Kienzle) } & \multicolumn{2}{|c|}{$\mathbf{F}_{\mathbf{C}}($ Kronenberg) } & \multirow{2}{*}{$\frac{\mathbf{F}_{\mathrm{fD}} \text { (Daar) }}{\mathrm{KN}}$} \\
\hline $\mathrm{Nmm}$ & $\mathrm{Nmm}$ & $\mathrm{Nmm}$ & $\mathrm{Nmm}$ & $\mathrm{KN}$ & $\mathrm{KN}$ & $\mathrm{KN}$ & $\mathrm{KN}$ & \\
\hline 2430 & 3480 & 4250 & 4480 & 0.382 & 0.436 & 0.701 & 0.887 & 1.30 \\
\hline
\end{tabular}
physical configuration, had a stationary shaft with no geometric variations, Fig. 3b. Although formed and fixed to the drill differently than another prototype, analysis parameters set of similarity between them. This condition was crucial since the SP, Fig. 4a, was also used in monitoring the effectiveness of the DP

Table 2 Theoretical maximum and minimum machining parameter values. 

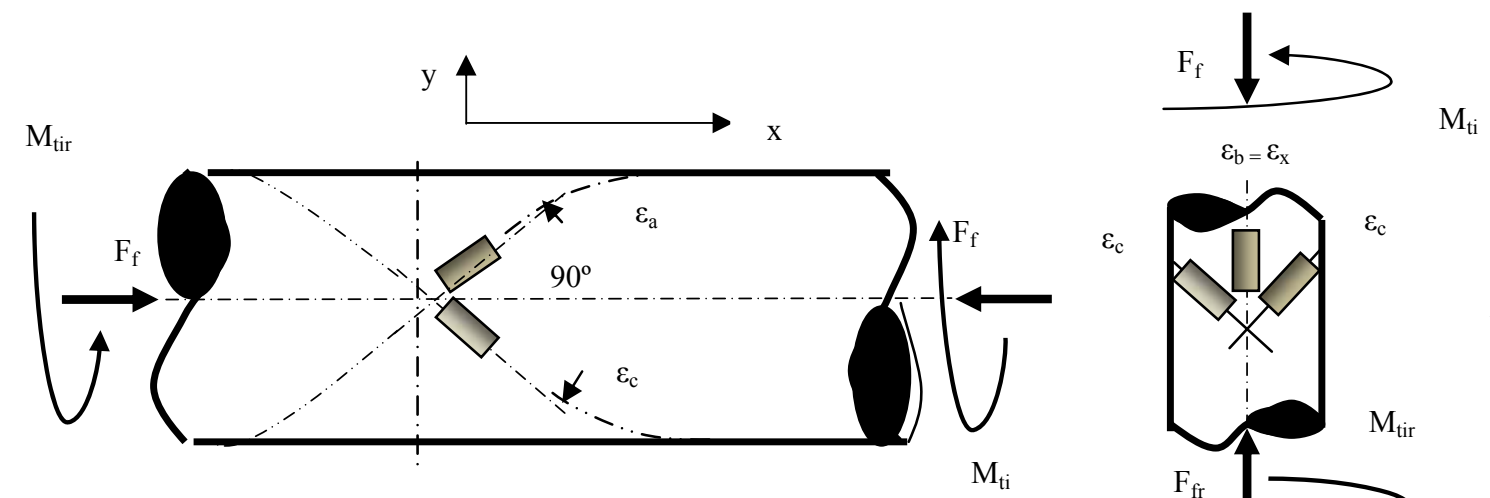

$\varepsilon_{\mathrm{c}}$

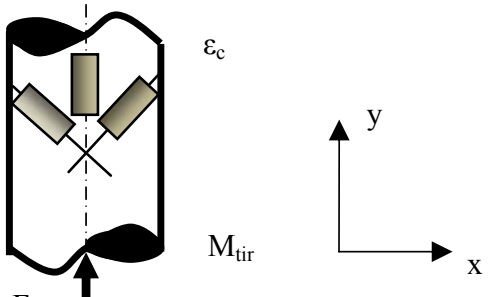

Fig. 3 Forces produced by drilling tools and their directions process and reaction: (a) DP and (b) SP.

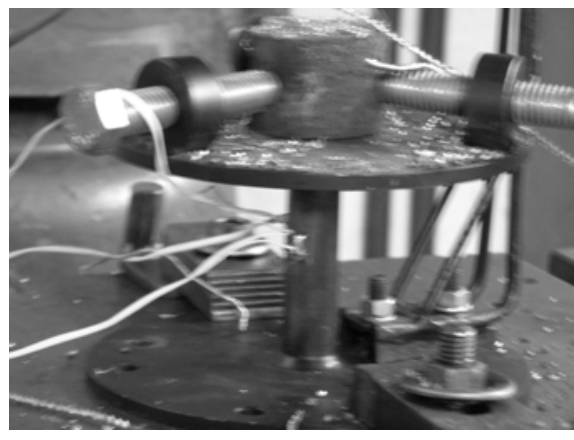

(a)

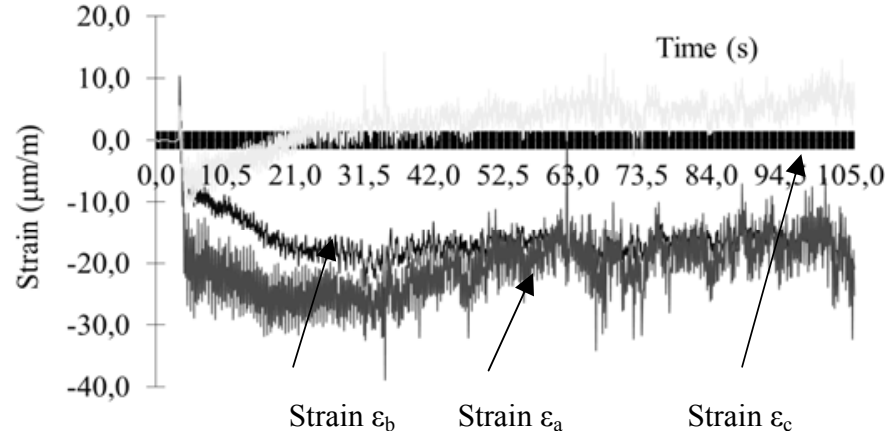

(b)

Fig. 4 (a) PE's general arrangement and (b) the rosette strain graph.

strain. In SP shaft were fixed superficially, three uniaxial strain gages, brand KYOWA, $120 \Omega$, G. F. 2.12. Its electrical interconnection was produced using a 1/4 WB circuit for each SG, yielding specifies three types of deformation: $\varepsilon_{\mathrm{a}}, \varepsilon_{\mathrm{b}} \varepsilon_{\mathrm{c}}$. The form of strain acquisition through rosettes clearly showed a compression force (represented by strain $\varepsilon_{b}$ ) and a torsion (represented by strains $\varepsilon_{\mathrm{a}}$ and $\varepsilon_{\mathrm{c}}$ ), Fig. $4 \mathrm{~b}$.

\subsection{DP Arrangement}

The general setup of the prototype is basically composed by a rotating shaft, where SGs were adjusted, pre-retirement plans and tooling to produce a machining operation. Its overall arrangement, Fig. $5 \mathrm{a}$, believed that the tools to be adapted on the shaft is a universal chuck for shape $\varnothing 12 \mathrm{~mm}$ drill fixation with use of internal Morse cone. This standard commercial element was essential to the geometric measurements of the PD spindle, which made of steel SAE 1020. Fig. 4b showed the result of shaft strain related to the moment.

\subsection{DP and SP Final Results in Experimental Way}

Through SP strains set thrust force in Fig. 6, the strain identified $\varepsilon_{\mathrm{b}}=\varepsilon_{\mathrm{x}}$ strain. From this strain $\left(\varepsilon_{\mathrm{x}}\right)$, a variable force $\left(F_{f}(t)\right)$ was determined using Eqs. (7-9), and is exhibited in Fig. 6. The thrust force, determined analytically by the Daar's Equation (Eq. (5)) shown in Table 2, was used as a reference line experimental result, obtained by Eqs. (6-8).

$$
\begin{gathered}
\varepsilon_{\mathrm{ai}}(\mathrm{t})=\varepsilon_{\mathrm{x}_{\mathrm{i}}}(\mathrm{t}) \cos ^{2} \theta_{\mathrm{ai}}+\varepsilon_{\mathrm{y}_{\mathrm{i}}}(\mathrm{t}) \operatorname{sen}^{2} \theta_{\mathrm{ai}} \\
+\gamma_{\mathrm{xyi}}(\mathrm{t}) \operatorname{sen} \theta_{\mathrm{ai}} \cdot \cos \theta_{\mathrm{ai}} \\
\begin{aligned}
\varepsilon_{\mathrm{bi}}(\mathrm{t})=\varepsilon_{\mathrm{x}_{\mathrm{i}}}(\mathrm{t}) \cos ^{2} \theta_{\mathrm{bi}}+\varepsilon_{\mathrm{y}_{\mathrm{i}}}(\mathrm{t}) \operatorname{sen}^{2} \theta_{\mathrm{bi}} \\
+
\end{aligned} \\
\begin{array}{r}
\varepsilon_{\mathrm{xyi}}(\mathrm{t})=\varepsilon_{\mathrm{x}_{\mathrm{i}}}(\mathrm{t}) \cos ^{2} \theta_{\mathrm{ci}}+\varepsilon_{\mathrm{y}_{\mathrm{i}}}(\mathrm{t}) \operatorname{sen}^{2} \theta_{\mathrm{ci}} \\
+\gamma_{\mathrm{xyi}}(\mathrm{t}) \operatorname{sen} \theta_{\mathrm{ci}} \cdot \cos \theta_{\mathrm{ci}}
\end{array} \\
\varepsilon_{1}, \varepsilon_{2}(\mathrm{t})=\frac{\varepsilon_{\mathrm{xi}}(\mathrm{t})+\varepsilon_{\mathrm{yi}}(\mathrm{t})}{2} \pm \sqrt{\frac{\varepsilon_{\mathrm{xi}}(\mathrm{t})+\varepsilon_{\mathrm{yi}}(\mathrm{t})}{2}+\left(\frac{\gamma_{\mathrm{xyi}}(\mathrm{t})}{2}\right)^{2}}
\end{gathered}
$$




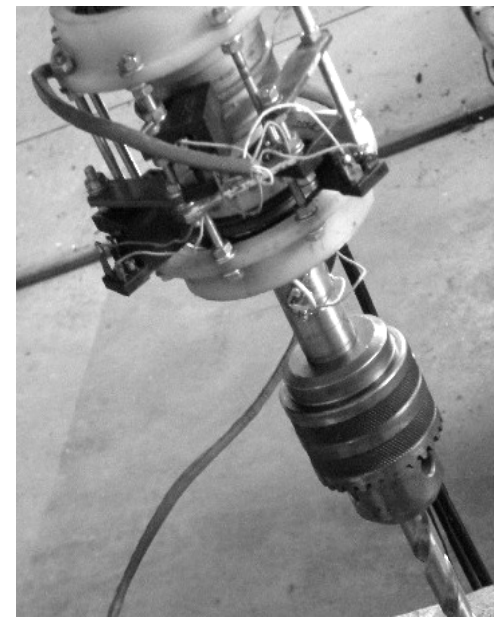

(a)

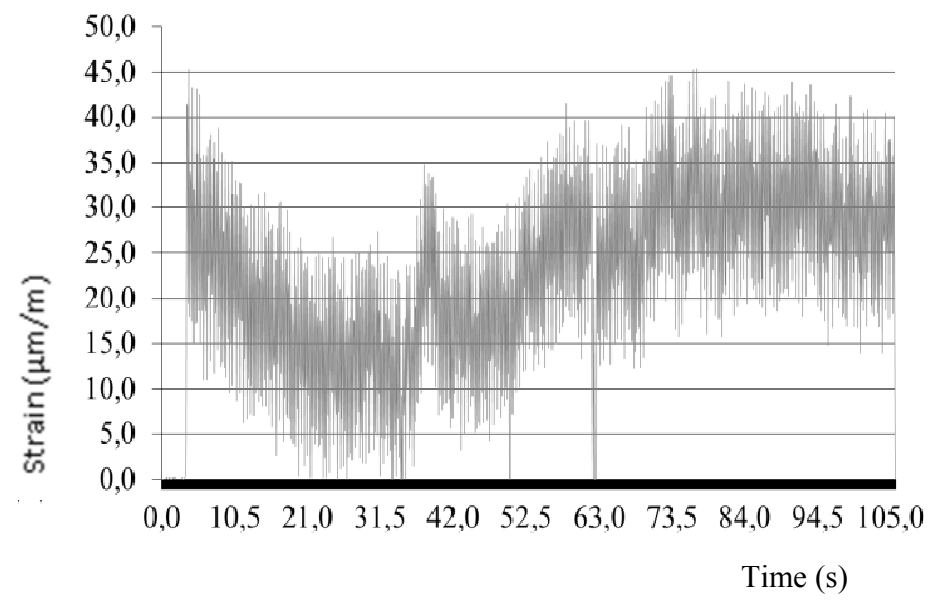

(b)

Fig. 5 (a) General Assembly DP and (b) strain graph ics.

Time (s)

$0,0 \quad 10,521,0 \quad 31,542,052,5 \quad 63,0 \quad 73,5 \quad 84,0 \quad 94,5105,0$

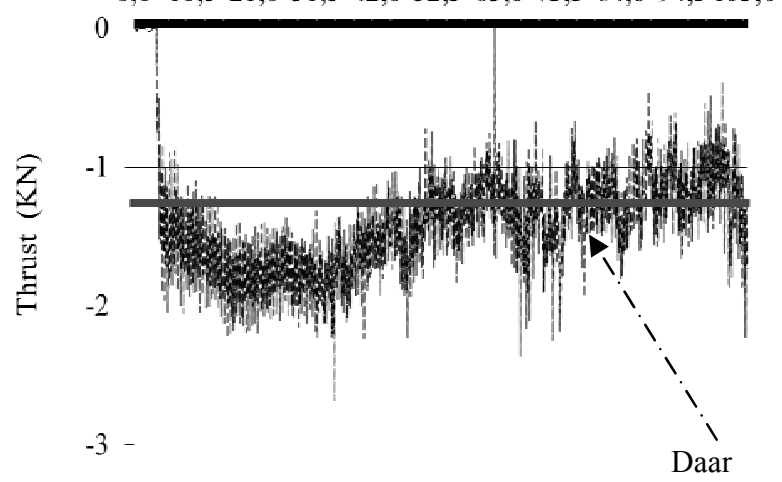

Fig. 6 Thrust force in time domain and its limits to DP and SP.

$$
\begin{gathered}
\left|\varepsilon_{1}\right|(\mathrm{t})=\varepsilon_{\mathrm{i}}(\mathrm{t}) \\
\varepsilon_{\mathrm{i}}(\mathrm{t})=\frac{\frac{\mathrm{F}_{\mathrm{f}}(\mathrm{t})}{\mathrm{A}}}{\mathrm{E}} \rightarrow \mathrm{F}_{\mathrm{f}}(\mathrm{t})=\varepsilon_{1}(\mathrm{t}) \cdot \mathrm{E} \cdot \mathrm{A} \\
\mathrm{F}_{\text {fan }}=\left(\frac{\sum_{\mathrm{i}=1}^{\mathrm{p}}\left(\mathrm{F}_{\mathrm{ai}}\right)^{2}}{\mathrm{p}}\right)^{\frac{1}{2}}
\end{gathered}
$$

where, E was the elastic modulus, A was the shaft cross sectional area in ERE position and $\varepsilon_{\mathrm{i}}=\varepsilon_{\mathrm{b}}=\varepsilon_{\mathrm{x}}$ was the specific strain in the direction $(\mathrm{x})$.

From Eq. (8), it was possible to derive the thrust force $\left(\mathrm{F}_{\mathrm{f}}(\mathrm{t})\right)$ and its amplitude variations in time domain $\left(\Delta \mathrm{F}_{\mathrm{f}}(\mathrm{t})\right)$, shown in Fig. 6. Eq. (9) gave the average end $\left(\mathrm{F}_{\text {fam }}\right)$ in order to relate to the results presented summary analytically in the Table 2.

Torsional moment variations with respect to time domain for SP and DP were produced and shown in the Figs. 7 and 8 and Eqs. (10-13).

Fig. 9 showed the final result about two forms of experimental simulation analysis for multiaxial machining efforts in the time domain model. The result was divided into three stage and defined in the following way: a) Concerning DP: stage (1) showed no noise and vibration set in the tool advancement process; stage (2) initially established a peak variation movement to win the starting inertia. Then the tool advancement process shows a decrease of the mean torsional moment with an amplitude variation due to drilling initializaion; stage (3) represented the evolution and balance of torcional moment, maintaining high amplitude variation relative to SP, so that the tip drill no longer press the inside of the hole; b) Concerning SP: stage (1) showed no noise and vibration set in the tool advancement process; as stage (2) starts, the drilling showed an increase of the torsional moment intensity and its variation range, as the drill bit too deep in the hole; stage (3) showed evolution of the torsional moment presenting a lower average amplitude variation relative to the DP until the drill tip no longer penetrates in the hole. 


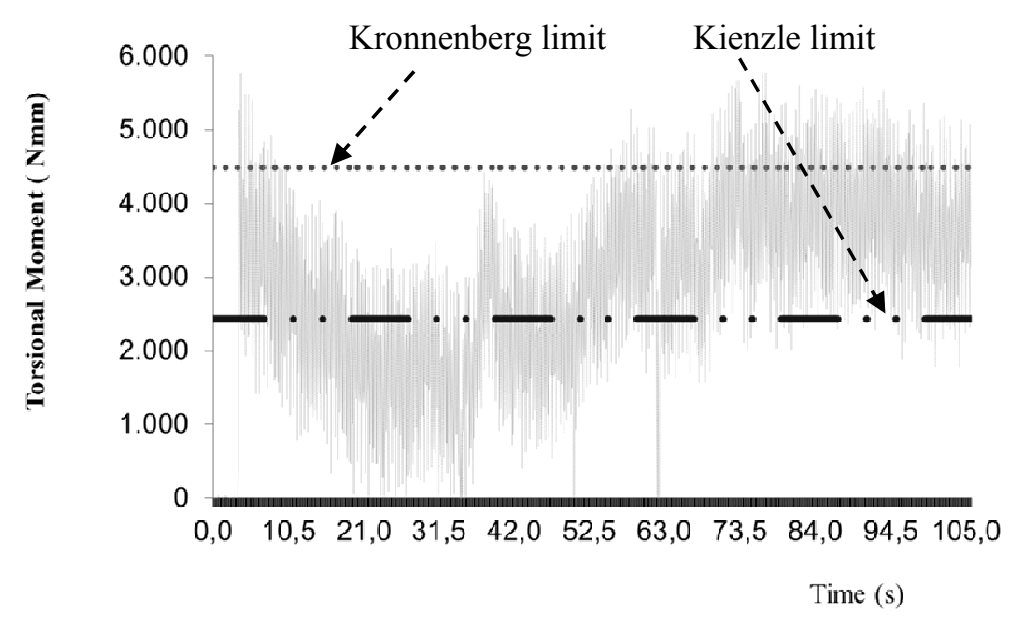

Fig. 7 Torsional moment in time domain and its limits (PD).

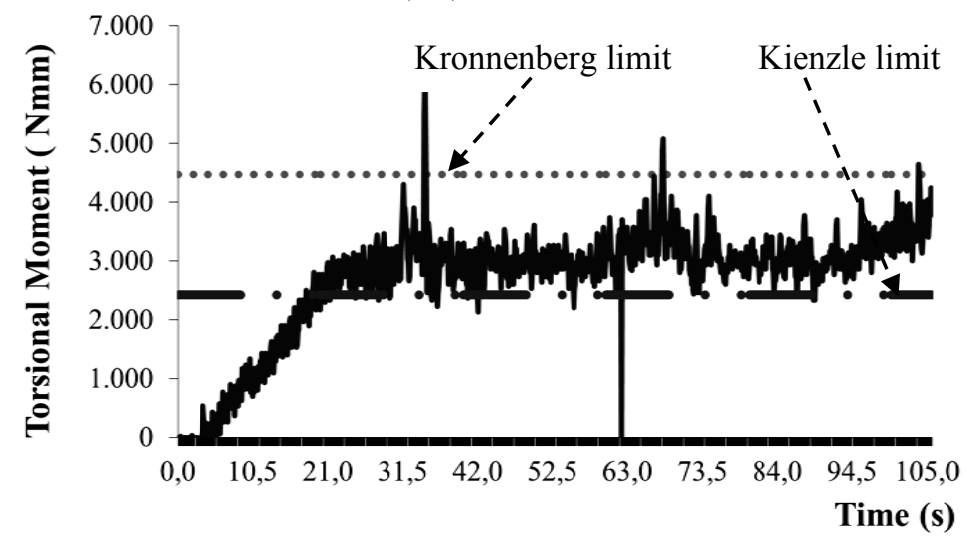

Fig. 8 Torsional moment in time domain and its limits (SP).

Table 3 Comparison between analytical and experimental machining thrust effort.

\begin{tabular}{lllc}
\hline Loading & Analytical form (CCT) & \multicolumn{2}{c}{ Experimental form (ccr) } \\
\cline { 3 - 4 } & & PD (RMS) & PE (RMS) \\
\hline $\mathrm{F}_{\mathrm{a}},(\mathrm{N})$ & $1260 / 1300$ & 1450 & \\
$\mathrm{M}_{\mathrm{t}},(\mathrm{N} \cdot \mathrm{mm})$ & $4480 / 2430$ & 3569 & 2875 \\
\hline
\end{tabular}

$$
\begin{gathered}
\gamma_{x y i}(t)=\frac{\varepsilon_{a i}(t)}{2}-\varepsilon_{x i}(t)-\varepsilon_{b i}(t) \\
\gamma_{\max _{i}}(t)=2 \sqrt{\frac{\varepsilon_{1 i}(t)-\varepsilon_{2 i}(t)}{2}+\frac{\gamma_{x y i}^{2}(t)}{2}} \\
=\left|\varepsilon_{1 i}(t)-\varepsilon_{2 i}(t)\right| \\
\tau(x, y)=f(\gamma, G, t) \rightarrow \tau_{\max _{i}}(t)=\varepsilon_{45^{\circ}}(t) \cdot G \\
\tau_{\text {max }_{i}}(t)=\varepsilon_{i}(t) \cdot G \rightarrow M_{t_{i}}(t)=\frac{\gamma_{x y i}(t) \cdot G \cdot J_{p}}{r} \\
M_{t_{\text {max }_{r m s}}}=\left(\frac{\sum_{i=1}^{p}\left(M_{t_{m_{x a x}}}\right)^{2}}{p}\right)^{\frac{1}{2}}
\end{gathered}
$$

$$
\mathrm{M}_{\mathrm{t}_{\text {min } \mathrm{rms}}}=\left(\frac{\sum_{\mathrm{i}=1}^{\mathrm{p}}\left(\mathrm{M}_{\mathrm{t}_{\mathrm{min}_{\mathrm{i}}}}\right)^{2}}{\mathrm{p}}\right)^{\frac{1}{2}}
$$

\subsection{Vibration Parameters}

The forced condition of a damped angular displacement $(\Theta)$ established the torsional vibration behavior. So it was possible to simplify the general equation for tooling movement, presented in Eq. (15) in the $\mathrm{x}$ and $\Theta_{\mathrm{Y}}$ directions (two degrees of freedom in a damping system). Taken into account SG strains, in an independent way, it was possible to analyze the vibration 


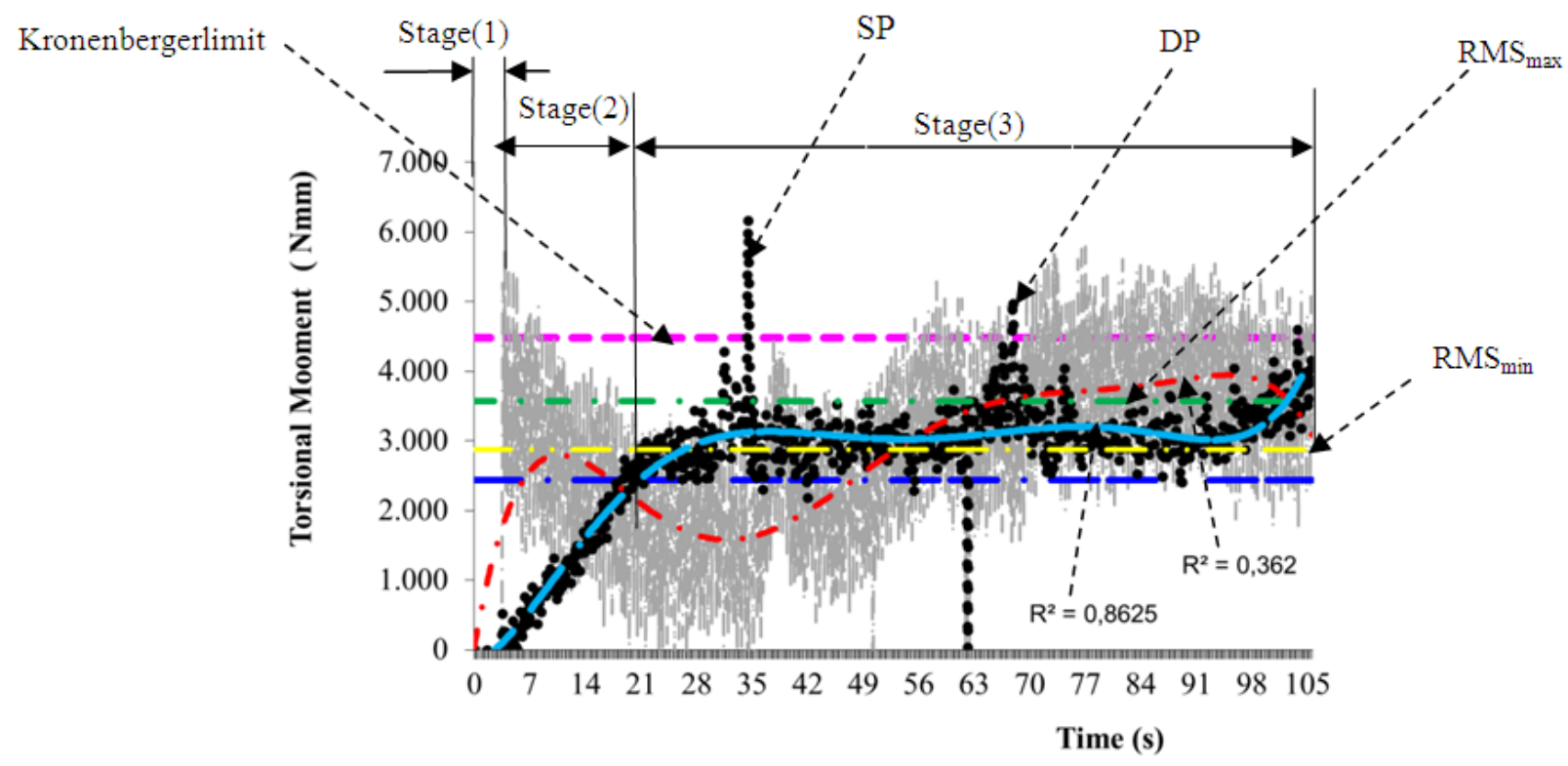

Fig. 9 Final result of torcional moment in time domain, its limits and their respective trend lines for DP/SP.

behavior considering the system as one freedom degree damping forced system, represented by the thrust force $\left(\mathrm{F}_{\mathrm{f}}\right)$ and force cutting $\left(\mathrm{F}_{\mathrm{c}}\right)$ using a simple differential equation that defines the set of vibration parameters, defined in Eqs. (15-16), and presented in Table 4 for DP and SP. Fig. 10 presented three different levels to indicate the point surface analysis about whirling marks.

$$
\begin{gathered}
{[M]\left\{\begin{array}{l}
\ddot{\mathrm{x}}_{\mathrm{c}}(\mathrm{t}) \\
\ddot{\theta}_{\mathrm{c}}(\mathrm{t})
\end{array}\right\}+[\mathrm{C}]\left\{\begin{array}{l}
\dot{\mathrm{x}}_{\mathrm{c}}(\mathrm{t}) \\
\dot{\theta}_{\mathrm{c}}(\mathrm{t})
\end{array}\right\}+[\mathrm{K}]\left\{\begin{array}{l}
\mathrm{x}_{\mathrm{c}}(\mathrm{t}) \\
\theta_{\mathrm{c}}(\mathrm{t})
\end{array}\right\}=\left\{\begin{array}{l}
\mathrm{F}_{\mathrm{c}}(\mathrm{t}) \\
\theta_{\mathrm{c}}(\mathrm{t})
\end{array}\right\}} \\
\mathrm{K}=\sum \mathrm{k}_{\mathrm{i}} \\
\zeta=\sqrt{\frac{\mathrm{r}^{2}-1}{-2}}=\frac{\mathrm{c}}{\mathrm{c}_{\mathrm{cri}}}=\frac{\mathrm{c}}{2 \mathrm{mw}}=\frac{\mathrm{c}}{2 \sqrt{\mathrm{mk}}} \\
\mathrm{w}_{\mathrm{n}}=\sqrt{\frac{\mathrm{K}}{\mathrm{m}}}, \mathrm{r}=\frac{\mathrm{w}}{\mathrm{w}_{\mathrm{n}}}, \mathrm{f}_{\mathrm{n}}=\frac{1}{2 \pi} \cdot \sqrt{\frac{\mathrm{K}}{\mathrm{J}_{\mathrm{p}}}}
\end{gathered}
$$

where, $\mathrm{m}$ was the total mass, $\mathrm{J}$ was the mass moment of inertia with respect to the central axis, $L_{i}$ is the length of each shaft section and Jp was the polar moment of inertia.

In Table 4, the prototype vibration parameters were presented. $\mathrm{G}$ was the shear modulus, $\mathrm{K}$ was the stiffness coefficient, c was the damping coefficient, $\zeta$ was the damping ratio, $\omega_{\mathrm{n}}$ was the natural angular frequency, fn was natural oscillation frequency, $f_{n}$ was natural oscillation frequency, $\mathrm{w}$ was the excitation frequency, $w_{d}$ is natural damped frequency, $f$ was the oscillation frequency and $r$ was the frequency ratio. This results demonstrated that resonance did not take place $\left(w \neq w_{n}\right)$. The system behavior for the DP presented a large variation of intensity amplitudes $\left(\Delta \mathrm{M}_{\mathrm{c}}\right)$ in relation to the SP, shown in Table 5, although $r<1$ (DP and SP). Thus, considering Eq. 16, it was clear that the increased stiffness SP causes lesser amplitude variation $\left(\left(\Delta \mathrm{F}_{\mathrm{a}}\right)\right.$ than the PD one.

After the first hole, there was prepared a new specimen which nine holes were made in the same way as the first was produced, including the same tooling without modification. The rotational marks vibration presented the first hole were repeated in the remaining nine. It was then made a roughness surface analysis of each hole in each level shown in Fig. 10. It was noticed that the (longitudinal and transverse) roughness was the result of vibration and not the cause of vibration, showing no regularity from one hole to another, one as shown in Fig. 11, Tables 7 and 8. All holes had different shapes and different average values 
Table 4 Vibration parameters.

\begin{tabular}{llllllllll}
\hline & $\begin{array}{l}\mathbf{G} \\
\left(\mathbf{N} / \mathbf{m}^{2}\right)\end{array}$ & $\begin{array}{l}\mathbf{K} \\
(\mathbf{N} / \mathbf{m})\end{array}$ & $\begin{array}{l}\mathbf{c} \\
(\mathbf{k g} / \mathbf{s})\end{array}$ & $\zeta$ & $\begin{array}{l}\mathbf{w}_{\mathbf{n}} \\
(\mathbf{r a d} / \mathbf{s})\end{array}$ & $\begin{array}{l}\mathbf{f}_{\mathbf{n}} \\
(\mathbf{c p s})\end{array}$ & $\begin{array}{l}\mathbf{w} \\
(\mathbf{r a d} / \mathbf{s})\end{array}$ & $\begin{array}{l}\mathbf{f} \\
(\mathbf{c p s})\end{array}$ & $\mathbf{r}$ \\
\hline $\mathrm{PD}$ & \multirow{2}{*}{$\mathrm{e}^{10}$} & 7,525 & 160 & 0.6 & 80 & 488 & 27.2 & 4.3 & 0.34 \\
$\mathrm{PE}$ & 10,798 & 154 & 0.7 & 82 & 1170 & & 0.33 \\
\hline
\end{tabular}

Table 5 Variation of intensity amplitudes behavior $\left(\Delta \mathbf{M}_{\mathbf{c}}\right)$.

\begin{tabular}{|c|c|c|c|}
\hline & Level 1 (37.5 S) & level $2(54.0 \mathrm{~S})$ & level $3(75.0 \mathrm{~S})$ \\
\hline $\begin{array}{l}\text { Máx } .10^{3} \\
\text { Min.10 } \\
\Delta .\left(10^{3}\right)\end{array}$ & 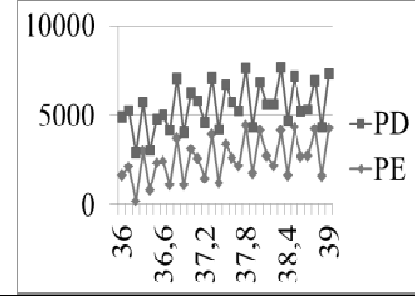 & 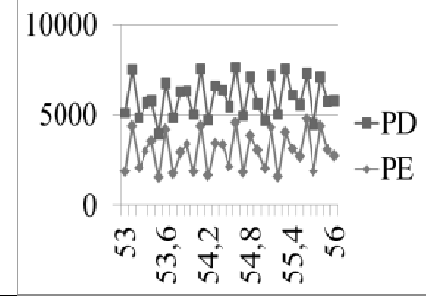 & 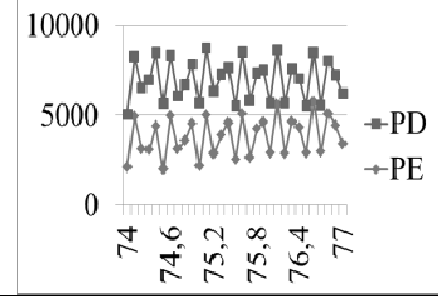 \\
\hline $\begin{array}{l}\mathbf{M}_{\mathrm{tmax}} / \mathbf{M}_{\mathrm{tmin}} / \Delta \mathbf{M}_{\mathrm{Tpd}} \\
(\mathbf{N m m}) \\
\mathbf{M}_{\mathrm{tmax}} /, \mathbf{M}_{\mathrm{tmin} /} \Delta \mathbf{M}_{\mathrm{tPE}} \\
(\mathbf{N m m})\end{array}$ & $1.76 / 1.0 / 0.06$ & $1.69 / 1.61 / 0.08$ & $3.43 / 1.71 / 1.70$ \\
\hline
\end{tabular}

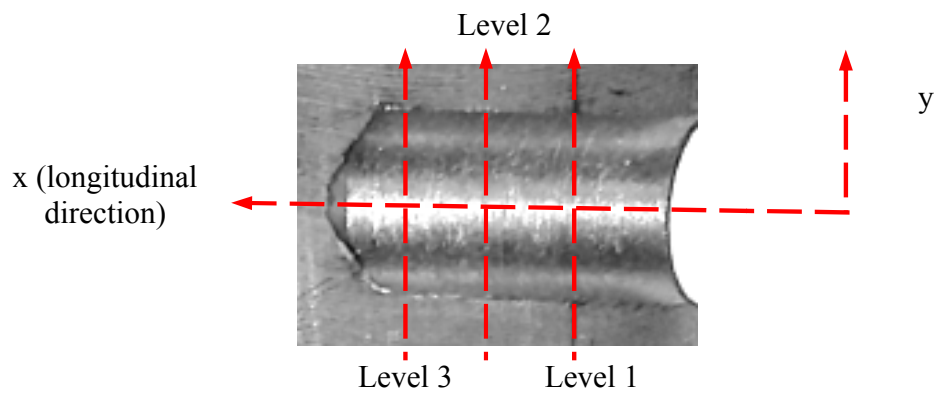

Fig. 10 Hole perfectly round, smooth surface with whirling marks on surface and bottom.

of roughness surface at different levels, however the transverse profile was always larger than longitudinal.

Fig. 11 showed different holes with different surface roughness in several analysis level as indicated in Fig.10.

Although not using a short drill $(\mathrm{L} / \mathrm{D}=2)$, it was assumed, in this work, that deflection in $\mathrm{x}$ and $\mathrm{y}$ directions does not occur on DP and SP shafts, but there is an influence of both axial and torsional vibration, characterized in variations amplitudes shown in Figs. 6-8. Figs. 12-14 present the results of simulation of torcional and flexional vibration in time domain. Frequency domain analysis, by FFT was also made. So Fourier spectra of DP and SP are also shown in Figs. 12-14. In the Fourier spectra the same frequencies, with different anplitudes, are dominant, and the largest peak occurs respectively at $1.219 \times$
$10^{4-3}$ (thrust force), $1.208 \times 10^{-3}(\mathrm{SP})$ and $1.216 \times$ $10^{-3} \mathrm{~Hz}(\mathrm{DP})$.

\section{Results and Discussion}

Figs. 6 and 9 indicated both the existence of variation in intensity of thrust force (axial vibration) as a moment of intensity variation in torsional drill penetration test body.

Table 7, Figs. 10 and 11 showed typical marks of torsional vibration, variable in time domain, on the hole surface. Since there was no resonance in the rotation applied to the procedure and the relationship between frequencies have a frequency ratio $(r<1)$ very similar to DP and SP, the variation in intensity of torque $(\Delta \mathrm{Mt})$, Table 5 and vibration parameters that described in Table 4 showed that comparing the stiffness value $(\mathrm{k})$ of SP and DP, it can be noticed that 
the smaller intensity variation $(\Delta \mathrm{Mt})$ was related to a greater stiffness. Thus, higher the frequency ratio $(r>0$ and $r \neq 1$ ), the greater the reduction in amplitude of vibrations occurred, which were already perceived considering the stiffness of SP in relation to the PD one.

The maximum peaks of moments $\left(\Delta \mathrm{M}_{\mathrm{tmax}}\right)$ of the
DP defining were out of analytical limit. The trend line of each DP remains within the limits, however, the trend line of does SP present a $\mathrm{R}^{2}=86 \%$, whereas the DP has just a $\mathrm{R}^{2}=38 \%$, Fig. 9 . The evolution of the range of variation of intensity of torsional moment in both SP and DP established three different stages of

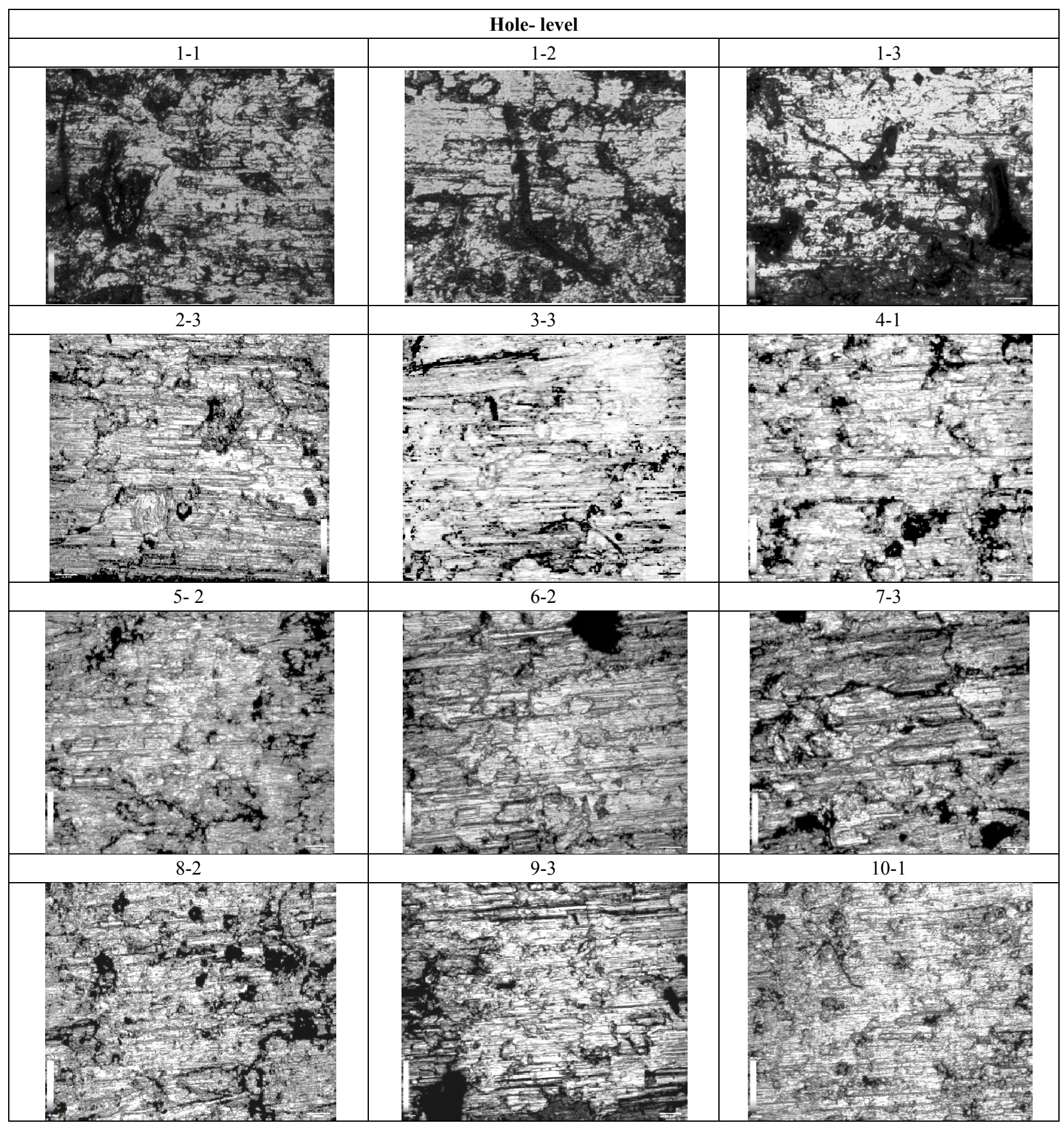

Fig. 11 Hole perfectly round, smooth surface with whirling marks on surface and bottom. 
process. Stage 1 was characterized by the approach of the tool to the specimen. Stage 2 started with the drilling, considering the geometric phase change of the tool. It continued until the drill tip is fully within the hole. Stage 3 was characterized by the deepening of the hole until it stops. The greatest intensity was related variation to a tool wear during the drilling process, the variation of thickness and hardness of the chip material, the variation of the friction coefficient on the incidence surface between the tool and the specimen influencing the quality of the surface roughness in the longitudinal and transverse direction.

Table 7 General analysis about roughness surface.

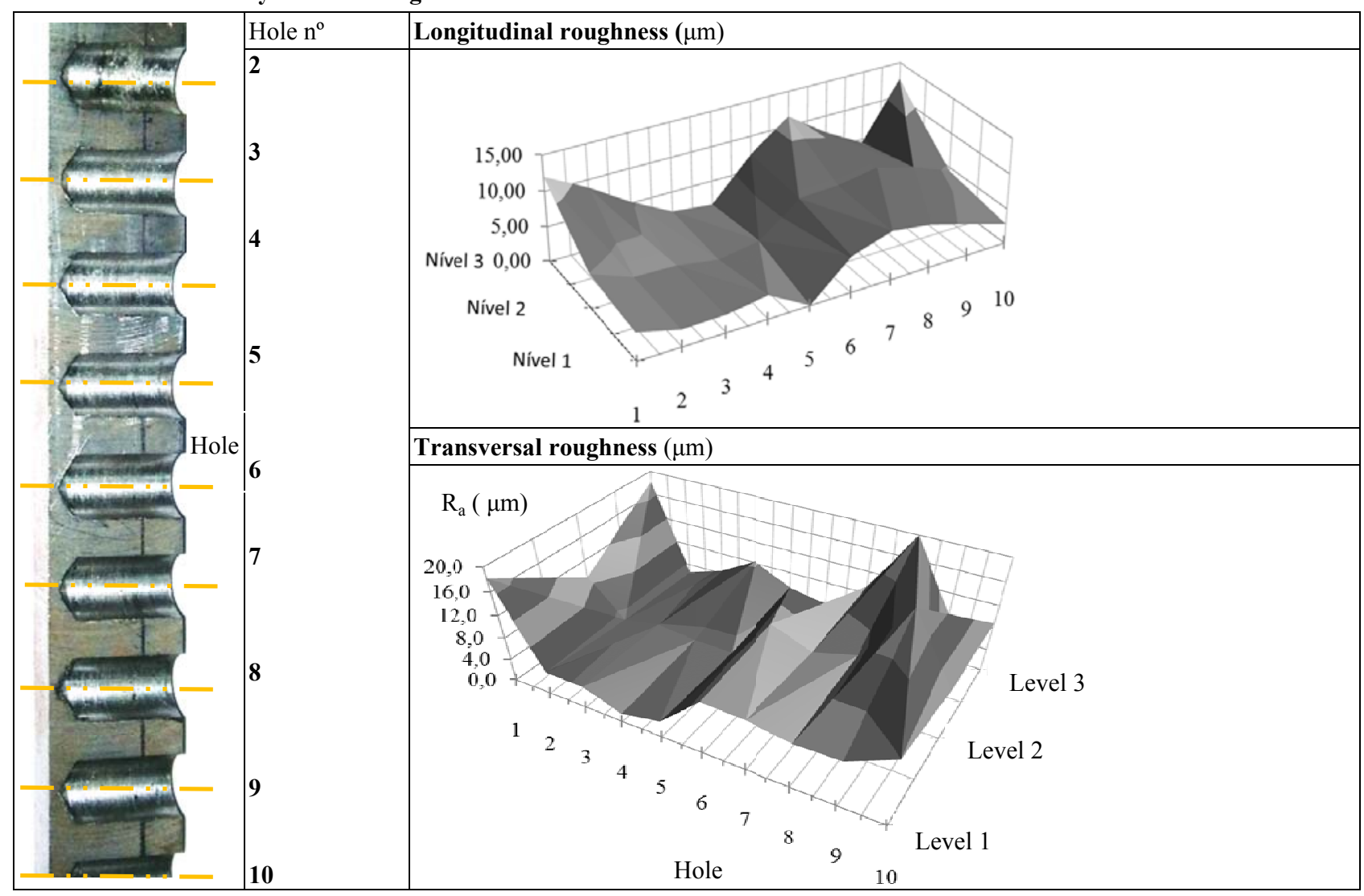

Table 8 General assessment of the levels roughness.

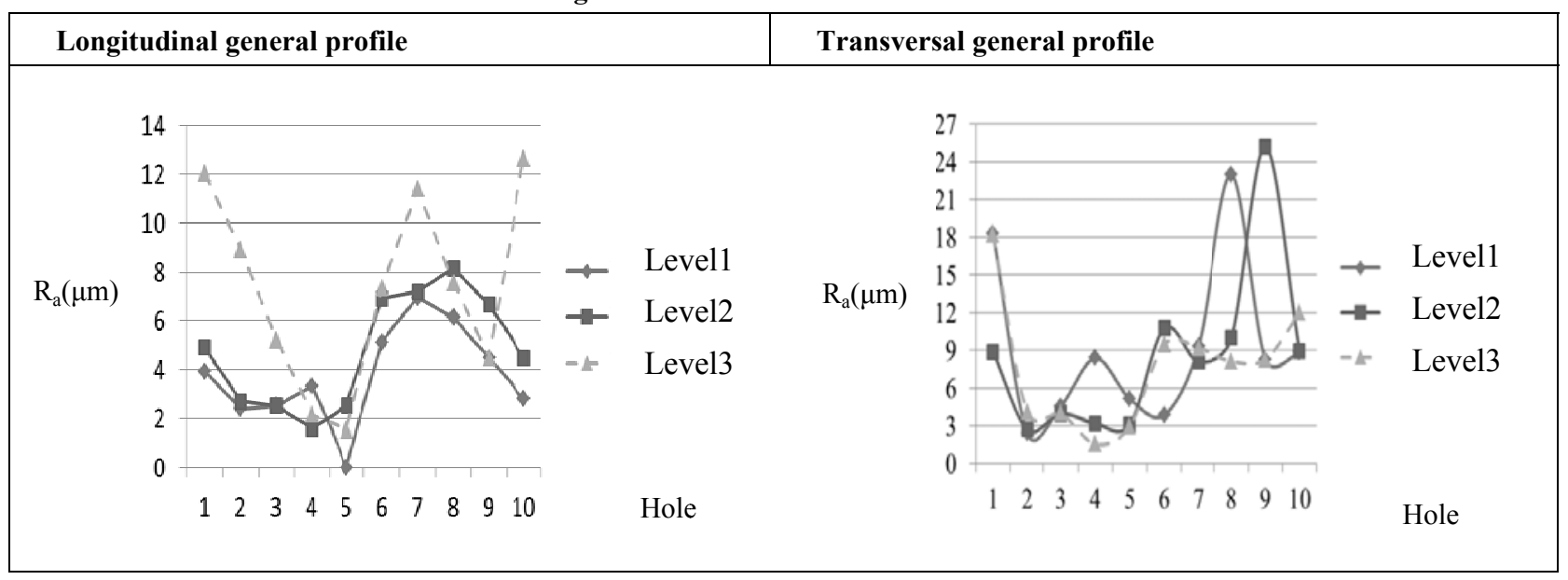




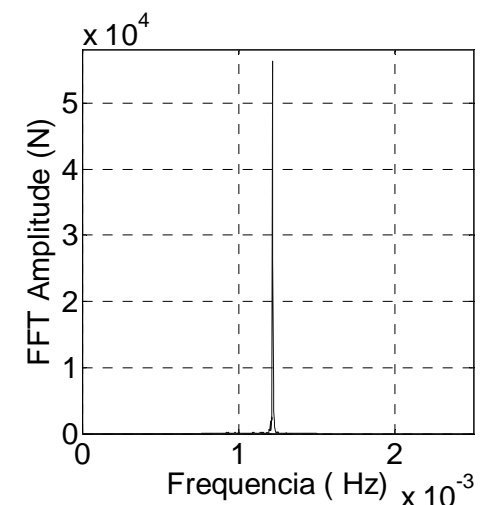

(a)

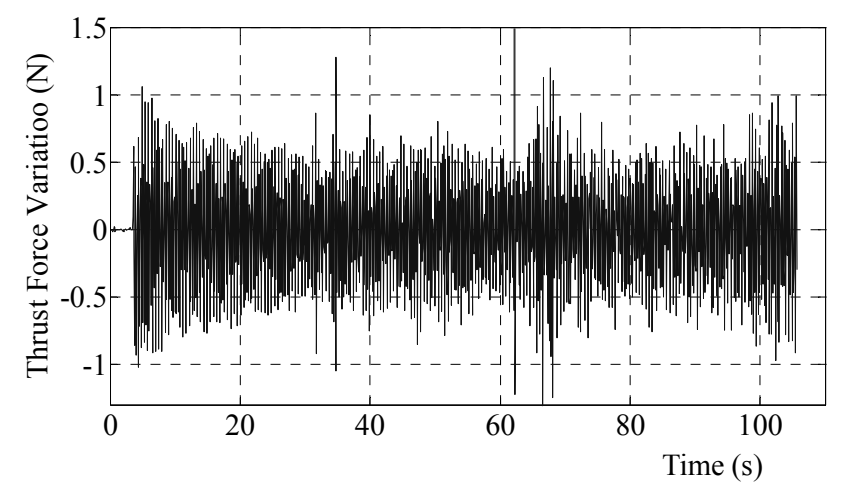

(b)

Fig. 12 Analysis of Thrust force vibration in the frequency domain (a) and in the time domain (b).

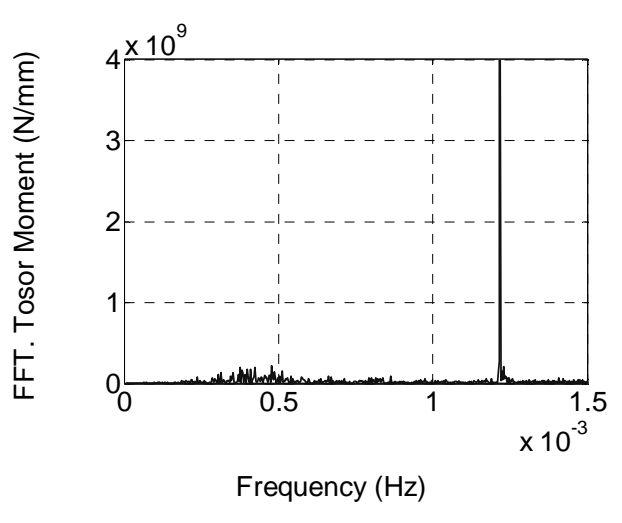

(a)

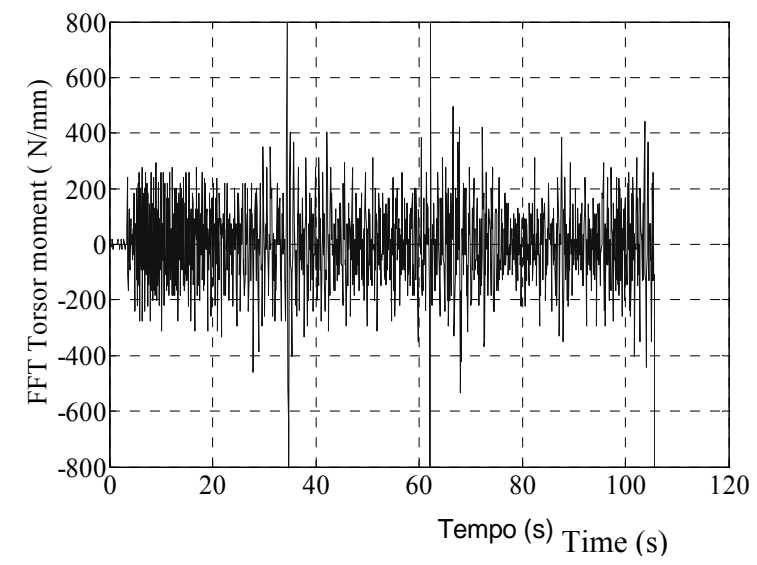

(b)

Fig. 13 Vibration analysis in the frequency domain (a) and time domain (b) SP.

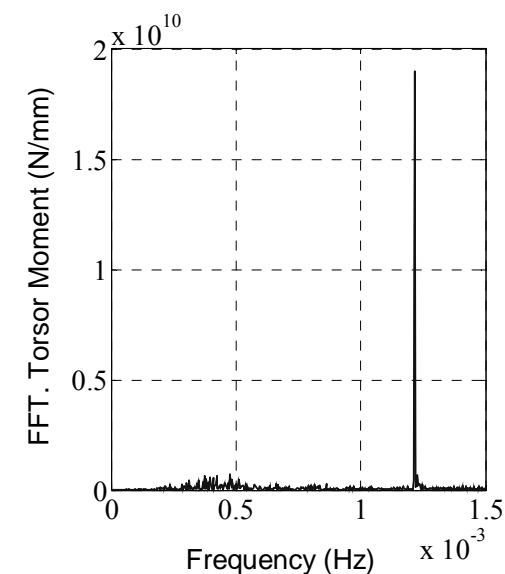

(a)

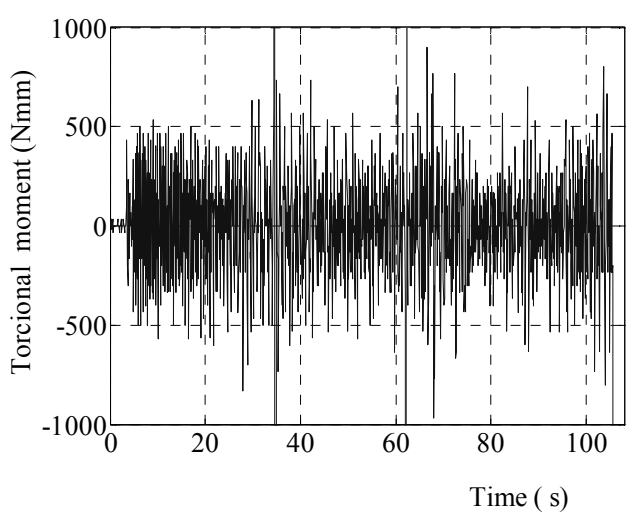

(b)

Fig. 14 Vibration analysis in the frequency domain (a) and in time domain (b) DP.

\section{Conclusions}

This study proposes an analysis of the machining efforts based on experimental strains results, in the time domain, taking into consideration the design and construction of two prototypes. Although Figs. 7-9 showed a graph with different behavior between SP and DP in drilling process, the acquired analogic 
signal of the reproduced strains, in both shafts, were consistent with multi-axial loading patterns, which were satisfactorily related to the analytical results. The lower stiffness was the fundamental condition for the most irregular behavior of the DP momentum intensity variation. A greater shaft rigidity allowed a greater rotation speed of the drilling process, yielding a better surface quality and a reduced amplitude variation of the surface deformations. Both prototypes (SP and DP) present the same fundamental frequency with different amplitudes, as shown in Figs. (13-14). DP torsional moment had the largest amplitude variation of intensity regarding the SP one in time domain.

The differentiated way SGs were arranged and interconnected to the Wheatstone Bridge (WB) have established the condition so that the DP only assimilates strains produced by twisting. In the SP, on the other way, the SGs were adjusted in order to assimilate all the influence strains produced during a machining process, as showed in Figs (4a-5b). So it was possible to analyze the vibration behavior considering the system as a damped forced system with one degree of freedom, using a simple differential equation that defines the set of vibration parameters, represented by Eqs. (15-16).

The main objective of the analysis of the machining efforts was exhibited in Figs. (6) and (9). These figures allowed us to make considerations about the surface roughness represented in Figs. (10) and (11) and Tables 5, 7 and 8, where it could be noticed and proved that the (longitudinal and transverse) surface roughness was the result of vibration and not the cause of vibration although the transverse profile had been always larger than longitudinal one.

\section{References}

[1] Castro, L. R., Viéville, P. S. and Lipinski, C. P. 2006. "Correction of Dynamic Effects on Force Measurements Made with Piezoelectric Dynamometers." International Journal of Machine Tools \& Manufacture. 46: 1707-15.

[2] Du, R., Yang, J. A. and Jaganathan, V. 2002. "A New Dynamic Model for Drilling and Reaming Processes." International Journal of Machine Tools \& Manufacture 42: 299-311.

[3] Karabay, S. 2005. "Design Criteria for Electro-Mechanical Transducers and Arrangement for Measurement of Strains Due to Metal Cutting Forces Acting on Dynamometers." Materials and Design.

[4] Mousavi, S. V. and Gagnol, R. P. 2013. "Machining Prediction of Spindle-Self-Vibratory Drilling Head." Journal of Materials Processing Technology.

[5] Roukema, J. C. and Altintas, Y, 2006. "Time Domain Simulation of Torcional Axial Vibrations in Drilling." International Journal of Machine Tools \& Manufacture 146: 2073-85,

[6] Roukema, J. C. and Altintas, Y. 2007. "Generalized Modeling of Drilling Vibrations Part I: Time Domain Model of Drilling Kinematics, Dynamics and Hole Formation." International Journal of Machine Tools \& Manufacture.

[7] Santos, D. C. Barbieri, R. 2011. "Design and Construction of a Torque Wrench" Revista matéria, COPPE UFFRJ.

[8] Strenkowski, J. S., Hsieh, C. C. and Shih, A. 2004. "An Analytical Finite Element Technique for Predicting Thrust Force and Torque in Drilling." International Journal of Machine Tools \& Manufacture.

[9] Huang, B. W., Lin, A. D., Chen, Y. C. and Kuang, J. H. 2008. "A Dynamic Model for a Drill in the Drilling Process." World Academy of Science and Technology. 2: 234-40

[10] Zeilmann, R. P. and Vacaro, T. 2008. "Application of Steel-Fast Bits in Dry Machining Steel AISI P20", Estudos Tecnológicos.

[11] Diiniz, A. E. 2008. Tecnologia da usinagem dos materiais, edited by Artliber Ltda, São Paulo. Brasil. 